\title{
POSSIBILIDADES DE ATUAÇÃO DO PSICÓLOGO ESCOLAR DIANTE DE DIFICULDADES NO ÂMBITO ESCOLAR
}

\author{
POSIBILIDADES DE LA ACCIÓN DEL PSICÓLOGO ESCOLAR DELANTE DE LAS \\ DIFICULTADES EN EL ÁREA ESCOLAR
}

\section{ACTION POSSIBILITIES OF THE SCHOOL PSYCHOLOGIST'S IN FRONT SCHOOL DIFFICULTIES}

\author{
Elisabeth ROSSETTO ${ }^{1}$ \\ Fabrício Duim RUFATO ${ }^{2}$ \\ Geovane dos Santos da ROCHA ${ }^{3}$
}

RESUMO: $\mathrm{Na}$ atualidade, vários fatores têm refletido no ambiente escolar, tais como a hiperatividade, a desatenção e o desinteresse. Diante de tais situações, os agentes escolares têm buscado contribuições da psicologia para melhoria das queixas apresentadas. À vista disso, o presente artigo, embasado nas contribuições da Psicologia Histórico-Cultural, objetiva desenvolver um estudo teórico bibliográfico das possibilidades de atuação do psicólogo escolar diante de dificuldades comportamentais no ambiente escolar. Tais possibilidades de atuação são divididas conforme os focos de ação: os agentes escolares, os alunos, os responsáveis e/ou a comunidade escolar. Espera-se, por meio deste estudo, que os conhecimentos da psicologia possam tornar-se cada vez mais difundidos e servir de instrumentos mediadores para o processos de ensino e aprendizagem.

PALAVRAS-CHAVE: Psicologia histórico-cultural. Dificuldades comportamentais. Ambiente escolar.

RESUMEN: Actualmente, varios factores se han reflejado en el entorno escolar, como la hiperactividad, la falta de atención y el desinterés. Ante tales situaciones, los agentes escolares han buscado aportes de la psicología para mejorar las quejas presentadas. Por ello, este artículo, basado en los aportes de la Psicología Histórico-Cultural, tiene como objetivo desarrollar un estudio bibliográfico teórico de las posibilidades de actuación del psicólogo escolar ante las dificultades conductuales en el ámbito escolar. Dichas posibilidades de actuación se dividen según el foco de actuación: agentes escolares, estudiantes, tutores y/o comunidad escolar. Se espera, a través de este estudio, que el conocimiento de la psicología pueda llegar a ser cada vez más extendido y servir como instrumentos mediadores del proceso de enseñanza-aprendizaje.

\footnotetext{
${ }^{1}$ Universidade Estadual do Oeste do Paraná (UNIOESTE), Cascavel - PR - Brasil. Docente do Programa de PósGraduação em Educação. Doutorado em Educação (UFRG). ORCID: https://orcid.org/0000-0002-4581-2446. Email: erossetto2013@gmail.com

${ }^{2}$ Universidade Estadual do Oeste do Paraná (UNIOESTE), Cascavel - PR - Brasil. Doutorando no Programa de Pós-Graduação em Educação. ORCID: https://orcid.org/0000-0002-0514-3882. E-mail: fabriciorufato@hotmail.com

${ }^{3}$ Universidade Estadual do Oeste do Paraná (UNIOESTE), Cascavel - PR - Brasil. Mestrando no Programa de Pós-Graduação em Educação. ORCID: https://orcid.org/0000-0002-4706-3426. E-mail: geovanesdarocha@outlook.com
} 
PALABRAS CLAVE: Psicología histórico-cultural. Dificultades de comportamiento. Ambiente escolar.

ABSTRACT: Currently, several factors have been reflected in the school environment, such as hyperactivity, inattention and disinterest. Faced with such situations, school agents have sought contributions from psychology to improve the complaints presented. In view of this, this article, based on the contributions of Historical-Cultural Psychology, aims to develop a theoretical bibliographic study of the possibilities of performance of the school psychologist in the face of behavioral difficulties in the school environment. Such possibilities of action are divided according to the focus of action: school agents, students, guardians and/or the school community. It is expected, through this study, that the knowledge of psychology can become increasingly widespread and serve as mediating instruments for the teaching-learning process.

KEYWORDS: Historical-cultural psychology. Behavioral difficulties. School environment.

\section{Introdução}

A instituição escolar, vista como elemento fundamental para o processo de humanização do homem, promove ou possibilita por meio de suas ações, a internalização dos conhecimentos historicamente produzidos pela humanidade. É por meio da transmissão e assimilação dos saberes construídos e acumulados ao longo dos anos que se torna possível ao sujeito desenvolver suas características, particularidades e capacidades. Nesse cenário, a aprendizagem ocupa papel primordial, sendo a escola a instituição destinada ao ensino coletivo, isto é, à transmissão dos conhecimentos humanos.

Entretanto, alguns fatores podem refletir no ambiente escolar e na qualidade da vida acadêmica, ocasionando dificuldades consideradas anormais e patológicas. Dentre tais fatores influenciadores citam-se os familiares, econômicos, culturais, sociais e pedagógicos. Quando tais aspectos não são trabalhados e devidamente considerados, acabam por reduzir a escola, em muitas ocasiões, a um ambiente fracassado, como se tal local se resumisse à reprodução de informações pouco importantes e divergentes da realidade social.

Muitos alunos, por mais que tenham conhecimento da importância da educação para seu desenvolvimento e para sua carreira profissional, parecem não possuir motivação ou interesse com o bom andamento das práticas escolares. Em consequência, difundem-se de maneira crescente dificuldades de manejo comportamental em sala de aula. Nesse cenário, os agentes escolares ${ }^{4}$ têm se deparado com comportamentos tidos como hiperativos, desatentos, agressivos

${ }^{4} \mathrm{O}$ termo agentes escolares se refere ao quadro pedagógico que compõe a escola: professores, coordenadores e diretores. 
etc. O que se percebe é uma culpabilização do aluno na existência dessas problemáticas, em dissociação da realidade escolar e social. Isso faz com que sejam demandadas à psicologia, intervenções que resultem na melhoria das queixas apresentadas.

Assim, compreende-se que o papel do psicólogo escolar é, entre outros, o de trabalhar com o sentimento de culpabilização do aluno pelo seu fracasso escolar, amenizando suas dificuldades e desenvolvendo ações que maximizem o processo educacional e que corroborem com a melhoria da relação existente entre aluno e escola. Com base nessa premissa, o presente artigo objetiva, a partir de um estudo teórico bibliográfico pautado em autores como Lev Semionovitch Vigotski (1896-1934) e Alexis Nikolaevich Leontiev (1903-1979), além de estudos de Patto (1999), Meira (2000), Bernardes (2012), Souza (2000), entre outros, verificar as possibilidades de atuação do psicólogo escolar diante às dificuldades comportamentais encontradas no ambiente escolar. As dificuldades comportamentais aqui descritas aludem a quaisquer condutas consideradas desadaptadas e/ou que interfiram na aprendizagem escolar.

Para isso, iniciar-se-á a discussão com o destaque da relação existente entre a psicologia e a educação, de modo a compreender o surgimento e a manifestação de dificuldades comportamentais no âmbito escolar. A partir de então, serão apresentadas algumas possibilidades de atuação do psicólogo escolar diante de tais problemáticas. Elas serão expostas de acordo com o seu foco, isto é, os próprios agentes escolares, os alunos e os responsáveis e/ou comunidade escolar. Salienta-se que as intervenções apontadas estarão embasadas nas possibilidades de atuação científica da psicologia, como destacado pelo Código de Ética Profissional do Psicólogo (2005) - Resolução CFP nº10/2005.

Considera-se, que as dificuldades comportamentais que se fazem presentes no ambiente escolar, evidenciam situações em que a escola, enquanto instituição atrelada ao processo de humanização do homem, apresenta maiores dificuldades para proporcionar a transmissão e assimilação da cultura. Conforme destaca Souza (2000), existe um universo de questões institucionais, políticas, individuais, estruturais e de funcionamento no cotidiano escolar que muitas vezes conduzem suas atividades ao fracasso. O psicólogo desponta nesse cenário como um dos profissionais responsáveis por desvelar as múltiplas causalidades das problemáticas escolares, propondo intervenções que possibilitem à escola desempenhar sua função. Portanto, espera-se, por meio dos resultados do presente artigo, que os conhecimentos da psicologia possam tornar-se cada mais difundidos e possam servir de instrumento para o processos de ensino e aprendizagem. 


\section{Psicologia e educação}

As instituições escolares, ao desenvolverem práticas que medeiam a aquisição dos conhecimentos historicamente construídos, proporcionam condições para que os sujeitos da educação desenvolvam suas potencialidades caracteristicamente humanas. De acordo com Bock (2003), a escola está atrelada ao processo de humanização do homem, uma vez que desenvolve mediações pedagógicas que permitem com que os sujeitos entrem em contato com o conhecimento e, consequentemente, desenvolvam suas funções psicológicas superiores. $\mathrm{O}$ trabalho educativo, de tal modo, possui a intenção de direta e intencionalmente mediar a internalização dos conhecimentos desenvolvidos no desenrolar histórico.

Para que haja a apropriação do desenvolvimento histórico das aptidões humanas, faz-se necessário que o ser humano, como expõe Leontiev (1978), entre em contato com os fenômenos do meio social por intermédio de outros semelhantes. Isso porque, as aptidões humanas não são dadas e internalizadas através de fenômenos objetivos, mas são construídas ao longo da vida por meio das inter-relações com outros seres humanos. De tal maneira, a humanidade - em especial a criança - aprende as atividades adequadas no coletivo e por meio da mediação do outro. Tal fenômeno caracteriza um processo de educação.

Leontiev (1978) destaca que a educação pode possuir formas muito diversas, bem como diferentes níveis. Nas primeiras fases do desenvolvimento da humanidade, o processo educativo se relacionava, como ainda o é para as crianças pequenas, por uma simples imitação dos atos presentes no meio. Posteriormente, há especialização dos conhecimentos e constituição de formas mais complexas de ensino, como a educação escolar. Quanto mais a humanidade progride, mais complexa e rica em elementos se torna o processo educativo e as tarefas desempenhadas pela escola.

No entanto, a aprendizagem não é por si só equivalente a desenvolvimento. Como destaca Vigotski (2005), faz-se necessário com que se organize a aprendizagem à criança de modo a conduzir o seu desenvolvimento psíquico. Por meio disso, ativa-se um grupo de processos que estão em desenvolvimento, ou seja, a ativação do desenvolvimento ocorre por meio da aprendizagem, sendo ela um momento intimamente necessário para que as características humanas não naturais se constituam. Assim, o processo de desenvolvimento e o processo de aprendizagem não coincidem e não se apresentam de forma paralela, pois o processo de desenvolvimento segue o de aprendizagem.

De tal maneira, para Vigotski (2005), a aprendizagem é um requisito necessário para o desenvolvimento das funções psicológicas superiores (FPS), que são formadas social e 
culturalmente. Entende-se, por FPS, fenômenos psíquicos especificamente humanos que, com base em Martins (2013), referenciam processos de domínio de meios externos de desenvolvimento cultural, como a linguagem, a escrita, o cálculo e o desenho, bem como funções especiais não limitadas com exatidão, como a atenção voluntária, a memória lógica e a formação de conceitos. Ao contrário das funções psicológicas elementares (PSE), que se qualificam como biológicas e instintivas, as FPS são desenvolvidas culturalmente e, por este motivo, carregam caráter intencional e de controle consciente.

A aprendizagem da criança, necessária para o desenvolvimento das FPS, começa a ocorrer em um momento muito anterior ao da aprendizagem escolar. Contudo, é por meio das instituições escolares que se possibilita a apresentação sistematizada do conteúdo e que se gera, consequentemente, desenvolvimento. Assim, a aprendizagem estimulada nas escolas faz surgir nos alunos novas formas de analisar, planejar, raciocinar, memorizar etc. que se convertem em aquisições internas para ela. Isso proporciona ao sujeito a constituição de suas próprias aptidões, ou seja, a escola está atrelada ao processo de desenvolvimento dos caracteres tipicamente humanos.

De acordo com Meira (2000), a evolução das FPS está interligada com a forma pelas quais o indivíduo se apropria das experiências históricas. Por meio do trabalho educativo, possibilita-se ao aluno entrar em contato com os conhecimentos que foram historicamente desenvolvidos e acumulados pela humanidade, sendo eles, os elementos responsáveis por constituir o indivíduo e seus processos psicológicos. Assim, o trabalho educativo possui o intuito de produzir a humanidade nos indivíduos, isto é, a educação exerce papel primordial na construção da subjetividade humana.

Leontiev (1978) expõe que a criança se depara, desde seu nascimento, com elementos culturais que foram elaborados pelas gerações que o antecederam. Essa herança cultural engloba tanto as produções materiais quanto as elaborações intelectuais que foram produzidas no percorrer da história. Assim, cada geração humana começa sua existência, segundo o autor, com base nos elementos que foram criados pelas gerações precedentes. É por meio da apropriação dessas riquezas culturais que se desenvolvem as aptidões, especificamente humanas, ou seja, cada indivíduo aprende a ser homem por meio da incorporação da cultura.

Martins (2016) expõe que a apropriação dos conhecimentos humanos não ocorre de forma natural, pois depende da aprendizagem para a sua ocorrência. Isso se deve às raízes sociais do desenvolvimento, que vai do social para o individual. Bernardes (2012) destaca que as condições criadas pelas particularidades da vida em sociedade proporcionam condições para o desenvolvimento, isto é, as relações estabelecidas com outras pessoas (interpsíquicas) 
originam as características individuais (intrapsíquicas). A escola desponta nesse cenário como o principal meio de efetivação da aprendizagem, ou seja, caso ela não cumpra seu papel, o desenvolvimento dos sujeitos fica comprometido, não sendo possível alcançar as máximas possibilidades humanas.

A ciência psicológica, ao inserir-se no âmbito da educação, objetiva - considerando o exposto - potencializar o encontro do sujeito humano e a educação, o que gera consequente desenvolvimento das potências humanas. Para que isto seja possível, torna-se imprescindível, com base em Meira (2000), a compreensão dos processos psicológicos, dos processos pedagógicos e suas correlações: a educação exerce importante papel para a construção da subjetividade humana e esta, por sua vez, na construção do processo educacional. O psicólogo escolar, de tal forma, deve ter clara a função da escola: um espaço de (re)apropriação do saber e, consequente, reflexão sobre a finalidade de suas práticas.

Dentro deste encadeamento, a psicologia escolar pode ser entendida - com base em Meira (2000) - como uma área de atuação e um campo de exercício profissional dentre as possíveis à psicologia. Ao inserir-se no âmbito educacional e pretendendo atuar de modo crítico, o psicólogo escolar deve valer-se de diferentes elaborações teóricas da própria ciência psicológica, bem como da pedagogia, filosofia, entre outras. De tal forma, assumem-se compromissos teóricos e práticos com as questões próprias da escola e que se tornam focos de atuação e intervenção.

Evidencia-se, nesse ponto, a ocorrência de diversas situações contrárias ao objetivo educacional. O fracasso escolar desponta aqui, talvez, como o maior exemplo da falha no encontro entre o sujeito humano e a educação. Tal fenômeno é relacionado na maioria das ocasiões com inabilidades ou com a ausência de motivação do estudante para com o processo educacional. Entretanto, essa questão não deve ser vista como uma relação mantida somente com a própria pessoa, mas também definida de acordo com as relações sociais e com os determinantes histórico-culturais.

Como se discorrerá mais adiante, existem diversas determinações para o fracasso escolar, sendo que o trabalho e o discurso da Psicologia não devem se posicionar de acordo com os compromissos ideológicos em vigor na sociedade - buscando tornar o anormal normal -, mas sim pensar o homem como um ser histórico e social. Por meio da promoção de práticas críticas, possibilita-se o desenvolvimento e o uso de habilidades/capacidades do homem transformar sua realidade e, neste processo, transformar a si mesmo. Tal aspecto será discutido mais profundamente no item que se segue. 


\section{O fracasso escolar e os problemas comportamentais}

Como evidenciado anteriormente, as situações e condutas que não se enquadram nos comportamentos considerados adequados/normais são reduzidos a fracassos da escola e de sua função. Patto (1999) caracteriza o termo fracasso escolar como um rendimento escolar mais baixo, com maus resultados de aprendizagem. Este desempenho pode ser fruto do método de ensino, do corpo docente, dos fatores socioeconômicos, entre outros. Faz-se importante ressaltar que o fracasso escolar engloba também os aspectos de evasão escolar, indisciplina e problemas de conduta, assim como a falta de motivação e interesse para com o processo educacional.

Segundo Cordié (1996), a noção de fracasso escolar é uma construção recente, tendo surgido no fim do século XIX com a instauração da escolaridade obrigatória. A elaboração do fracasso escolar - de cunho até patológico, com a produção concomitante de distúrbios de aprendizagem - demonstra a preocupação da sociedade para com indivíduos que não se adaptam ao sistema cultural predominante. A casuística dos distúrbios de aprendizagem demonstra uma exigência da sociedade para com o desempenho escolar esperado, associada a expressões próprias dos alunos. Nesse último aspecto, o sujeito se expressa de forma singular frente aos mal-estares ocasionados pela pressão social.

Em contraponto a este aspecto duplo da casuística, o fracasso escolar tem sido entendido majoritariamente como um fracasso do aluno frente às demandas apresentadas pela escola. As compreensões que não atribuem ao aluno as causas do insucesso o colocam, contudo, em condições exteriores à escola - como as desigualdades sociais e o âmbito familiar -, excluindo possíveis participações da própria instituição de ensino (CARVALHO, 1997). Salienta-se que não se trata aqui de encontrar culpados ou de deslocar a culpa a outros agentes, mas entender a complexidade do fenômeno apresentado.

Nesse encadeamento, três elementos são destacados por Carvalho (1997) como envolvidos nos processos de ensino e aprendizagem e, consequentemente, na produção do fracasso escolar. Para o autor, há alguém que ensina: os professores e as instituições escolares - a forma pela qual se ensina pode não ser a melhor ou a mais adequada aos alunos; há algo que é ensinado: a disciplina ou a habilidade específica - aquilo que se ensina pode estar além das possibilidades de entendimento do aluno no momento atual; e há alguém a quem se ensina: os alunos.

De tal modo, torna-se infundada a designação de que o aluno ou a sua família seriam os culpados pelo insucesso; deve-se se considerar todos os aspectos envolvidos no contexto onde 
a criança encontra-se inserida. Conforme exposto por Collares e Moysés (1989), é de suma importância a realização de construções e elaborações críticas sobre o não cumprimento da função da escola, da sociedade, considerando tal fracasso como um problema social politicamente produzido.

Leontiev (1978) expõe, nesse sentido, que os diferentes níveis de desenvolvimento das formas e aptidões intelectuais são produzidos por relações fragmentadas na sociedade em que a produção humana não é disponibilizada para todos os indivíduos. Isso gera níveis de desenvolvimento divergentes entre os indivíduos, que não são oriundos de diferenças biológicas naturais, mas de desigualdades econômicas e de classes. A concentração das riquezas materiais por uma classe social específica/dominante ocasiona também a concentração das riquezas culturais intelectuais por essa classe. Isso faz com que o acesso às faculdades humanas seja divergente aos indivíduos, isto é, alguns acabam por ter um mínimo de contato com o desenvolvimento cultural necessário ao desenvolvimento das FPS.

Outro ponto importante para a compreensão do fracasso escolar pode ser caracterizado, como Bock (2003) descreve, nas ideias de educação única para todos e na concepção de que o ser humano é dotado de capacidades inatas - aptidões dadas por uma forma de instinto inato e, assim, não desenvolvidas. Nessa perspectiva, as diferenças entre as pessoas se dariam pelas distintas formas com que cada um se engaja e aproveita as condições oferecidas pelo meio. Tal compreensão não considera, assim, as singularidades e as diferentes formas de aprender evidenciadas pelos alunos, apostando em métodos e formas de ensino únicos e tradicionais.

O fracasso escolar, contudo, não deve ser interpretado como ocasionado por uma prática pedagógica fragilizada dos professores. Meira (2000) relata, nesse sentido, que os professores estão submetidos a diversas situações adversas de trabalho, tal como sentimento de impotência e desesperança. O psicólogo escolar, segundo a autora, deve contribuir com a melhoria da situação docente e das práticas pedagógicas, resgatando a autonomia, o papel dirigente do ensino e o valor social do professor. Além do mais, deve desenvolver práticas que propiciem a formação de vínculos entre os sujeitos que compõem a escola, contribuindo com o máximo desenvolvimento das relações sociais na instituição.

Tais elementos evidenciam a complexidade do fenômeno apresentado. Assim, ao se discutir o fracasso escolar, deve-se considerar a ampla gama de fatores envolvidos, não se resumindo a uma culpabilização do aluno. Contudo, não se pode negar a existência das dificuldades de comportamento, de aprendizagem e as deficiências que fazem parte do ambiente escolar. Considerando esse contexto, pauta-se em Vigotski (2001), ao reportar-se a esse sujeito 
como alguém que se desenvolve de maneira peculiar, podendo alcançar os mesmos níveis de desenvolvimento que indivíduos sem deficiências ou dificuldades.

Conforme exposto por Vigotski e Luria (1996), todas as crianças apresentam condições para aprender, tendo elas deficiências ou não. Logo, devem-se investigar possíveis recursos mediadores pedagógicos para o desenvolvimento das funções psicológicas superiores. Rosseto (2012) expõe, nesse sentido, que o processo educativo, o contexto cultural/social no qual a criança se encontra e as condições, quer sejam subjetivas ou de adaptação, são os elementos determinantes à aprendizagem e ao desenvolvimento. Tal perspectiva resulta na compreensão de que todo ser humano aprende, porém se faz necessário criar condições para que possa ultrapassar suas limitações.

A partir da discussão do fracasso escolar como produzido social e historicamente nos modos de funcionamento da sociedade, pode-se dispender olhares diferenciais sobre os problemas comportamentais que acontecem no âmbito educacional. A hiperatividade, a desatenção, a agressividade, a dominação e o desinteresse, sem citar outros, encontram explicação para a sua presença. Antes de apresentarmos possíveis estratégias de trabalho com tais problemáticas, cabe definir cada uma delas, conforme aparecem nos manuais nosográficos e/ou nas definições dadas por perspectivas psicopatológicas das vivências escolares. Ao final de cada tópico, realizamos uma breve discussão sobre as problemáticas, contudo, as contribuições serão feitas no item subsequente.

a) Hiperatividade: este quadro abarca todas as condutas (hiper)ativas dos alunos no ambiente escolar que atrapalham seu rendimento e seus relacionamentos (fala demasiada, atividades motoras excessivas etc.). Alunos que apresentam tais comportamentos são normalmente classificados com a psicopatologia "Transtorno de Déficit de Atenção e/ou Hiperatividade (TDAH)". Marcelli (1998) realiza um discurso crítico dessa situação, discorrendo que a vida na contemporaneidade, em especial na escola, não é adaptada às necessidades motoras dos alunos. A infância, segundo o autor, encontra-se rodeada por grandes estimulações visuais, auditivas, táteis, entre outras, mas, em contraponto, exige-se concentração e inibição dos impulsos despertados.

b) Desatenção: se considera todas as ocasiões em que o foco dos alunos não está na atividade didática proposta. Assim como no item posterior, crianças com comportamentos desatentos frequentes são normalmente enquadradas na psicopatologia "Transtorno de Déficit de Atenção e/ou Hiperatividade (TDAH)”. Asbahr e Meira (2014) consideram que a atenção frente a uma determinada atividade ocorre a depender do sentido que ela venha a ter para o sujeito, o motivo que o faz agir. De tal modo, o aluno deve saber o motivo pelo qual vai estudar, 
sendo necessário que a atividade escolar tenha um sentido para ele. Em casos em que não ocorre o processo descrito, tornam-se comuns desatenções e desinteresses.

c) Agressividade: enquadram-se neste item as ações autoagressivas (dirigidas a si mesmo) praticadas pelos alunos, bem como as heteroagressivas (dirigidas a outrem). Além das práticas físicas (empurrões, isolamentos, brigas etc.), incluem-se as ações verbais (xingamentos, depreciações, humilhações etc.) possíveis de exercício. Oliveira (1996) considera que comportamentos como os citados, componentes de indisciplina, são resultantes das aprendizagens e das relações estabelecidas em todo o contexto social e cultural ao qual o indivíduo faz parte, bem como à dinâmica da própria instituição escolar.

d) Dominação: este quadro engloba condutas de oposição, negação, provocação, dominação e de desafios - as célebres ações de indisciplina. Os comportamentos aqui destacados parecem despontar como uma resposta dos alunos frente às formas de organização e funcionamento da instituição escolar e, de forma mais ampla, da sociedade em si - tal como discutido por Cordié (1996). Dificuldades nos relacionamentos podem ser também os desencadeadores das ações aqui descritas, contudo, em âmbito escolar, o enfoque e as atuações possuem um sentido próprio.

e) Desinteresse: este aspecto refere-se às situações em que o insucesso do aluno é explicado por sua falta de interesse e motivação para com as atividades escolares. Marchesi (2004) descreve quatro condições que conduzem a essa condição: a incompreensão da tarefa, quando o aluno não tem claro o que precisa ser feito e não compreende as explicações do professor; a falta de autonomia, onde precisa aceitar condições impostas por outrem, onde muitos o enfrentam com atitudes antiautoritárias; sentimento de incompetência, quando não se sente capaz de resolver tarefas ou compreender assuntos; e a própria falta de interesse, oriundo pela ausência de satisfação pessoal ao trabalhar determinados conteúdos, muitas vezes, por não haver ligação direta entre a forma de repasse de conteúdo com sua realidade.

\section{Possibilidades de atuação do psicólogo escolar}

A partir da discussão realizada até aqui, acredita-se ser possível trazer possibilidades de atuação do psicólogo escolar frente às problemáticas anunciadas. Apresentamos, incialmente, perspectivas teóricas que orientam nossa forma de compreender e atuar frente às dificuldades de cunho comportamentais, para então, especificar algumas intervenções elaboradas, conforme nossa experiência profissional. 


\section{Agentes escolares}

Os trabalhos a serem realizados com os agentes escolares - professores, coordenadores e diretores - despontam como primordiais para o bom andamento escolar, uma vez que são esses sujeitos que desenvolvem a atividade principal de ensino. Tal como destacado na Resolução CFP no 014/00 (CFP, 2000), faz parte das possibilidades de atuação do psicólogo escolar aplicar os conhecimentos psicológicos na escola por meio de análises e intervenções psicopedagógicas. $\mathrm{O}$ atuar pedagógico praticado pelos agentes escolares, de tal modo, necessita e ganha maior efetividade com as contribuições advindas da psicologia.

De acordo com Meira (2000), isso pode ocorrer através de debates que coloquem em xeque as explicações psicopatologizantes sobre os comportamentos dos alunos e que, ao mesmo tempo, promovam modificações voltadas à melhora da prática docente e do processo de ensino e aprendizagem. Nesse ponto, o exercício da função do professor, de mediar a aprendizagem dos alunos, realiza-se com a organização intencional das atividades propostas. Pasqualini (2010) discorre sobre isso, alegando que não é suficiente disponibilizar às crianças os objetos da cultura, é necessário organizar e mediar essas atividades. Logo, ao professor cabe a função de propor e executar atividades que envolvam os alunos no conteúdo estudado, respeitando suas singularidades e realidades. Perspectiva esta apresentada pelos autores e que coaduna com o proposto pela Psicologia Histórico-Cultural.

Juntamente com o psicólogo escolar, cabe ao professor refletir a respeito dos problemas que se fazem presentes na escola, como também propor alternativas de trabalho, discutir tais caminhos e realizar trabalhos em parceria com outros profissionais e instituições que possam contribuir com a qualidade no processo de escolarização dos alunos (SOUZA, 2000). Com base nisso, elencamos algumas ações que podem ser executadas e desenvolvidas pelo psicólogo escolar para favorecer o trabalho dos agentes escolares:

- Fornecimento de espaço de escuta aos professores que atuam com alunos que exibem dificuldades de comportamento. Perante situações de indisciplina, podem-se criar adversidades para o professor se relacionar e, consequentemente, trabalhar com os alunos em questão. Por meio de escutas e intervenções especializadas torna-se possível uma ressignificação das ocorrências e o emprego de posturas e condutas mais adaptativas.

- Criação e execução de grupos periódicos com os agentes escolares a fim de discutirem-se problemáticas próprias do ambiente. De forma conjunta e com aporte teórico de variados campos de conhecimento, podem-se delimitar planos de trabalho críticos e diferenciais para manejo com as dificuldades encontradas. 
- Frequência e acompanhamento em algumas ocasiões das aulas e/ou dos momentos em que os alunos estão apresentando dificuldades de comportamento. De tal modo, o psicólogo escolar pode recolher maiores dados sobre o aluno e a forma com que a escola se relaciona com ele, fornecendo recomendações, orientações e intervenções sobre os pontos passíveis de mudança.

- $\quad$ Execução de formações específicas aos agentes escolares sobre as dificuldades apresentadas pelas escolas, fornecendo-se compreensões sobre os comportamentos apresentados e possíveis manejos embasados em teorias psicológicas.

\section{Alunos}

Como anteriormente destacado, o fracasso escolar é majoritariamente relacionado a um fracasso do aluno, contudo, trata-se de uma dificuldade que se apresenta por meio dele, mas não o consideramos como causa principal - na maioria das ocasiões. Para tanto, as ações do psicólogo escolar com os alunos se direcionam, segundo Meira (2000), com o resgate do sentido das ações escolares, enquanto meio de transformação da realidade, contribuindo com a remoção dos obstáculos subjetivos que possam estar dificultando as práticas da escola. Nesse ponto, a participação dos alunos na definição do planejamento e das diretrizes educacionais é essencial para a condução dos interesses mediante a realidade dos mesmos.

Souza (2000) destaca que os alunos devem estar no centro do processo de crítica e reflexão das práticas psicológicas, uma vez que é por meio deles que se desmistificam as crenças do fracasso escolar e dos comportamentos desadequados. Assim, as intervenções elencadas a seguir visam colaborar com o processo educativo e com o desenvolvimento de um papel ativo do aluno no processos de ensino e aprendizagem. Elas se relacionam, principalmente, com formas de fornecimento da palavra e da expressão de seus modos de ser, agir e viver. Papel este que também é defendido pela Psicologia Histórico-Cultural, ao atribuir ao aluno um papel de sujeito ativo, participante do processo.

- Construção conjunta das regras de convívio no ambiente escolar. Tais regras devem estar consoantes ao regimento do estabelecimento de ensino, mas considerar também as necessidades, os interesses e as possibilidades dos alunos. Por meio de tal prática, fornece-se um papel mais ativo aos alunos, corroborando para o desenvolvimento de bons relacionamentos com os agentes escolares.

- Criação conjunta de estratégias visuais e concretas (cartazes, criação de regras, horários...) para nortear e favorecer condutas que promovam o desenvolvimento. 
- $\quad$ Fornecimento de ambientes de expressão e escuta para que o aluno possa falar sobre as dificuldades enfrentadas, estabelecendo-se, conjuntamente, maneiras da instituição de ensino ajudá-lo para o enfrentamento e possível superação.

- Realização de avaliação psicológica visando identificar possíveis psicopatologias, bem como efetivar as intervenções e os encaminhamentos necessários a partir da demanda. Esse aspecto deve ser amplamente embasado em teorias críticas de modo a não haver psicopatologização dos alunos.

- Criação e desenvolvimento de grupos psicológicos periódicos com os alunos tanto os com dificuldades de comportamento quanto os com atuação adaptadas - de modo a trabalharem-se questões específicas, fornecendo-se escuta, orientações e elaborações. Aqui se podem adotar como tema geradores: solidariedade, respeito, companheirismo, trabalho em grupo, empatia etc.

\section{Responsáveis e/ou comunidade escolar}

Como destacado pela Constituição Federal de 1988 (BRASIL, 1988) e pelo Estatuto da Criança e do Adolescente (BRASIL, 1990), é dever da família, da sociedade e do Estado assegurar todas as oportunidades para que crianças e adolescentes tenham pleno desenvolvimento. De tal modo, a família e a comunidade, onde se insere a instituição escolar, também apresentam responsabilidades para com o desenvolvimento dos alunos.

Meira (2000) descreve ser importante que o psicólogo escolar reflita com os pais e/ou responsáveis e a comunidade escolar sobre o papel social da escola, identificando formas de, conjuntamente, se garantir uma Educação de qualidade. Isso se dá, segundo a autora, pelo desenvolvimento de ações que ampliem a participação social na escola, com acompanhamento e apoio da população e dos pais e/ou responsáveis.

São algumas possibilidades de ação do psicólogo escolar:

- $\quad$ Participar de reuniões escolares com pais e mestres, a fim de realizar explanações sobre a função social da escola e maneiras com que os referidos agentes podem colaborar para com as dificuldades apresentadas.

- Realizar atendimentos com os responsáveis da criança com dificuldades de comportamento investigando possíveis problemáticas das relações familiares que podem interferir no comportamento escolar do aluno, fornecendo escuta especializada e intervenções/orientações adequadas. 
- Promoção de atividades conjuntas com a comunidade para o desenvolvimento da convivência com o próximo. Além do mais, muitos conhecimentos históricos e práticos podem ser intermediados por meio de tais atividades.

\section{Considerações finais}

A partir do estudo realizado, pode-se inferir que alunos que apresentam dificuldades de comportamento são, costumeiramente, encaminhados para serviços de psicologia, estando essa demanda, normalmente, relacionada com uma expectativa de dissolução dos entraves e das dificuldades que se evidenciam no ambiente escolar. Sob tal perspectiva, a problemática na maioria das vezes, é depositada exclusivamente no aluno ou em fatores externos à escola, como a família, havendo uma desconsideração do papel da instituição escolar e da sociedade na produção das problemáticas. De tal modo, uma maior compreensão da realidade que se presentifica nas escolas, deve considerar o fracasso escolar como produzido por múltiplos fatores, isto é, a dificuldade de comportamento deve ser analisada e discutida em suas variadas vertentes, ultrapassando a aparência primeira e imediata da problemática.

Comportamentos tidos como hiperativos, desatentos, dominadores, agressivos, desinteressados, entre outros, evidenciam situações de desencontro do sujeito com a educação, sendo o psicólogo escolar um dos profissionais responsáveis por trabalhar e possibilitar maneiras mais adequadas de expressão e convivência. O primeiro passo a se trilhar, sob nosso olhar, é o de analisar para além da aparência com que a queixa escolar chega para atendimento, investigando todos os fatores que podem estar envolvidos. Faz-se necessário pesquisar, discutir e refletir os elementos que se envolvem na problemática e os que a mantém. A Psicologia Histórico-Cultural desponta aqui como uma possibilidade de norte teórico ao profissional da psicologia, uma vez que possibilita uma visão ampliada e completa do homem, o compreendendo a partir das inter-relações que estabelece com os outros sujeitos de seu meio, dando ênfase ao social, ao cultural e a historicidade do ser humano.

Contudo, além do passo primeiro de questionamento da realidade, é necessário discutir com a comunidade escolar caminhos e intervenções que contemplem a complexidade do fenômeno. Existe, nesse sentido, uma ampla gama de elementos relacionais, individuais, institucionais, comunitários, familiares, pedagógicos, biológicos e sociais que se relacionam com as queixas apresentadas. Usualmente, as práticas do psicólogo escolar se voltam, exclusivamente, ao atendimento individual em uma vertente próxima ao da psicologia clínica. Entretanto, ao se considerar a etiologia das dificuldades de comportamento, outras ações devem 
ser pensadas e executadas de modo a contribuir com o desenvolvimento das atividades escolares e, consequentemente, com os processos de ensino e aprendizagem.

Consideramos importante destacar, que as próprias terminologias utilizadas para se referir às vivências escolares (hiperatividade, desatenção, desinteresse etc.) compõem formas de patologização de comportamentos próprios da infância, ou que não se adequam aos parâmetros pré-definidos como necessários para o bom andamento das práticas escolares. Nesse sentido, as intervenções do psicólogo escolar não devem se ater à sua modificação, tornando "normais" as condutas tidas como "anormais". Acreditamos que o caminho é descobrir, juntamente com os alunos, suas famílias e os agentes escolares, maneiras com que a escola possa cumprir sua função humanizadora, respeitando a individualidade dos seres inseridos na escola. Muitas das ações se voltarão, nesse sentido, à compreensão dos fatores que tem desencadeado a problemática, intervindo criticamente nos pontos que possam estar dificultando o bom andamento das práticas escolares.

Cabe ainda dizer, que nesse artigo, buscamos trazer algumas possibilidades de atuação ao psicólogo escolar que melhor contemplassem a complexidade dos fenômenos relacionados às dificuldades comportamentais. As intervenções foram separadas por focos, a saber, os agentes escolares, os alunos e os responsáveis e/ou comunidade escolar. Tais possibilidades não foram exaustivas, havendo outras - as destacadas foram enumeradas, conforme nossas experiências profissionais. Por meio de intervenções como as citadas, embasada em teorias como, por exemplo, a Psicologia Histórico-Cultural, pode-se potencializar a qualidade das práticas educativas e, assim cumprir com a função da escola, que para além de ensinar, busca formar e humanizar os sujeitos. Trata-se, de tal modo, de uma luta pela transformação das relações sociais, uma luta política para que o homem se constitua como um ser humano, respeitando suas diferenças.

\section{REFERÊNCIAS}

ASBAHR, F. S.; MEIRA, M. E. M. Crianças desatentas ou práticas pedagógicas sem sentido? Relações entre motivo, sentido pessoal e atenção. Nuances: estudos sobre Educação, Presidente Prudente, v. 25, n. 1, p. 97-115, 2014.

BERNARDES, M. E. M. Mediações simbólicas na atividade pedagógica: contribuições da teoria histórico-cultural para o ensino e a aprendizagem. Curitiba: CRV, 2012.

BOCK, A. M. B. Psicologia escolar: teorias críticas. São Paulo: Casa do Psicólogo, 2003. 
BRASIL. Constituição (1988). Constituição da República Federativa do Brasil. Brasília, DF: Senado, 1988.

BRASIL. Ministério da Justiça. Lei n. 8.069, de 13 de julho de 1990. Estatuto da Criança e do Adolescente. Brasília, DF, 16 jul. 1990. Disponível em:

http://www.planalto.gov.br/ccivil_03/leis/18069.htm. Acesso em 03 dez. 2020.

CFP. CONSELHO FEDERAL DE PSICOLOGIA. Resolução CFP n. 010/2005. Brasília, 2005. Disponível em: http://site.cfp.org.br/wp-content/uploads/2012/07/codigo-de-eticapsicologia.pdf. Acesso em 03 dez. 2020.

CFP. CONSELHO FEDERAL DE PSICOLOGIA. Resolução CFP n. 014/2000. Brasília, 2000. Disponível em: https://site.cfp.org.br/wpcontent/uploads/2006/01/resolucao2000_14.pdf. Acesso em 03 sdez. 2020.

COLLARES, C. A.; MOYSÉS, M. A. A. Educação, saúde e formação da cidadania na escola. Revista Educação \& Sociedade, Campinas, 1989.

CORDIÉ, A. Os atrasados não existem. Porto Alegre: Artes Médicas, 1996.

LEONTIEV, A. O desenvolvimento do psiquismo. Lisboa: Livros Horizonte, 1978.

MARCELLI, D. Manual de psicopatologia da infância de Ajuriaguerra. Porto Alegre: Artmed, 1998.

MARCHESI, A. Os alunos com pouca motivação para aprender. In: COLL, C.; MARCHESI, A.; PALACIOS, J. Desenvolvimento psicológico e educação 3: transtornos do desenvolvimento e necessidades educativas especiais. 2. ed. Porto Alegre: Artmed, 2008.

MARTINS, L. M. Fundamentos da Psicologia Histórico-Cultural e da Pedagogia HistóricoCrítica. In: PAGNONCELLI, C.; MALANCHEN, J.; MATOS, N. S. D. (Org.). O trabalho pedagógico nas disciplinas escolares: contribuições a partir dos fundamentos da pedagogia histórico-crítica. Campinas, SP: Armazém do Ipê, 2016. cap. 2, p. 49-93.

MARTINS, L. M. O desenvolvimento do psiquismo e a educação escolar: contribuições à luz da psicologia histórico-cultural e da pedagogia histórico-crítica. Campinas, SP: Autores Associados, 2013.

MEIRA, M. E. M. Psicologia Escolar: pensamento crítico e práticas profissionais. In: TANAMACHI, E.; SOUZA, M. P. R.; ROCHA, M. E. M. (Org.). Psicologia e educação: desafios teórico-práticos. São Paulo: Casa do Psicólogo, 2000.

OLIVEIRA, M. K. A indisciplina e o processo educativo: uma análise na perspectiva vygotskiana. In: AQUINO, J. G. (Org.). Indisciplina na escola: alternativas teóricas e práticas. São Paulo: Summus; 1996.

PASQUALINI, J. C. O papel do professor e do ensino na educação infantil: a perspectiva de Vigotski, Leontiev e Elkonin. In: MARTINS, L. M.; DUARTE, N. (Org.). Formação de professores: limites contemporâneos e alternativas necessárias. São Paulo: Editora UNESP; São Paulo: Cultura Acadêmica, 2010. p. 161-191. 
PATTO, M. H. S. A produção do fracasso escolar: histórias de submissão e rebeldia. 2. ed. São Paulo: Casa do Psicólogo, 1999.

ROSSETTO, E. Os sujeitos da Educação Especial a partir da perspectiva histórico-cultural. In: ROSSETTO, E.; REAL, D. C. (Org.). Diferentes Modos de narrar os sujeitos da educação especial a partir de... Cascavel, PR: EDUNIOESTE, 2012. p. 55-72.

SOUZA, M. P. R. A queixa escolar na formação de psicólogos: desafios e perspectivas. In: Psicologia e educação: desafios teórico-práticos. São Paulo: Casa do Psicólogo, 2000.

VYGOTSKY, L. S.; LURIA, A. R. Estudos sobre a história do comportamento: símios, homem primitivo e criança. Porto Alegre: Artes Médicas, 1996.

VYGOTSKY, L. S. Obras escogidas. Madrid: Machado Libros, 2001. t. 3.

VYGOTSKY, L. S. Aprendizagem e desenvolvimento intelectual na idade escolar. In: LEONTIEV, A. N. et al. Psicologia e pedagogia: as bases psicológicas da aprendizagem e do desenvolvimento, 3. ed. São Paulo: Editora Centauro, 2005. p.01-17.

\section{Como referenciar este artigo}

ROSSETO, E.; RUFATO, F. D.; ROCHA, G. S. Possibilidades de atuação do psicólogo escolar diante de dificuldades no âmbito escolar. Doxa: Rev. Bras. Psico. e Educ., Araraquara, v. 22, n. 00, p. e021002, 2021. e-ISSN: 2594-8385. DOI: https://doi.org/10.30715/doxa.v22i00.14541

Submissão em: 04/12/2020

Revisões requeridas em: 19/03/2021

Aceito em: 30/03/2021

Publicado em: 20/04/2021 